\title{
Carcinoma mucinoso invasor da mama e seus diagnósticos diferenciais na biópsia percutânea com agulha grossa
}

A biópsia mamária percutânea com agulha grossa (ou core biopsy) é, hoje, um procedimento validado para diagnóstico pré-operatório de lesões mamárias amplamente empregado nos EUA, na Europa e no Brasil. A biópsia com agulha grossa (BAG) foi desenvolvida com duas finalidades principais: (1) eliminar a necessidade de biópsia cirúrgica aberta em pacientes com lesões benignas e (2) diagnosticar, com mais acurácia, o câncer de mama (se in situ ou invasor), cuja definição é limitada na citologia/punção aspirativa com agulha fina (PAAF) ${ }^{(1)}$. A BAG apresenta vantagens sobre a PAAF como a obtenção de material para diagnóstico histopatológico, o fato de a maioria dos patologistas sentir-se confortável na interpretação das lesões, a possibilidade de classificação e graduação provisórias do carcinoma de mama e, ainda, a utilização do material para estudo imuno-histoquímico de marcadores preditivos em câncer de mama ${ }^{(2)}$. No entanto, há limitações diagnósticas na BAG e, em alguns tipos de lesão, o mais prudente é reservar o diagnóstico definitivo para a biópsia excisional ${ }^{(3)}$. Entre as lesões cuja definição é limitada na BAG incluemse hiperplasias atípicas (ductais e lobulares), lesões de células colunares com atipia (ou atipia plana), lesões papilíferas, cicatriz radial/lesão esclerosante complexa, lesões fibroepiteliais e lesões do tipo mucocele (MLL - em inglês, mucocele-like lesion) ou com secreção mucinosa ${ }^{(1,3)}$. As MLL são caracterizadas por cistos contendo mucina que podem romper, extravasando a mucina para o estroma adjacente. $\mathrm{O}$ epitélio que reveste os cistos pode variar de normal até atípico (padrão de hiperplasia ductal atípica e carcinoma ductal in situ) e também pode extravasar e flutuar na mucina, simulando carcinoma mucinoso invasor. Quando as MLL são observadas na BAG com amostra escassa e o epitélio exibe atipias, surge a dúvida: são apenas MLL ou uma amostra pouco representativa de carcinoma mucinoso invasor? Neste volume do JBPML, Zanetti e Ribeiro-Silva( ${ }^{(4)}$ fazem revisão sobre carcinoma mucinoso invasor da mama e seus diagnósticos diferenciais em BAG, discutindo possibilidades e limitações quando há escassez de material. Além da MLL, os autores abordam alterações fibrocísticas com mucina luminal, lesões papilíferas com áreas de secreção mucinosa, e fibroadenoma e tumor phyllodes, com áreas de degeneração mucinosa. É ressaltada a importância de correlacionar os aspectos patológicos diagnósticos de cada grupo de lesões com a clínica e os achados mamográficos e ecográficos e, diante de limitação amostral ou dificuldade em definir diagnóstico definitivo, aguardar a excisão cirúrgica completa da lesão para o diagnóstico final.

\section{Referências}

1. JOHNSON, N. B.; COLLINS, L. C. Update on percutaneous needle biopsy of nonmalignant breast lesions. Adv Anat Pathol, v. 16, n. 4, p. 183-95, 2009.

2. ANDRADE, V. P.; GOBBI, H. Accuracy of typing and grading invasive mammary carcinomas on core needle biopsy compared with the excisional specimen. Virchows -Arch, v. 445, n. 6, p. 597-602, 2004.

3. BILOUS, M. Breast core needle biopsy: issues and controversies. Mod Pathol, v. 23, p. S36-45, 2010.

4. ZANETTI, J. S.; RIBEIRO-SILVA, A. Carcinoma mucinoso invasor da mama e seus diagnósticos diferenciais em biópsia por agulha grossa: revisão da literatura. J Bras Patol Med Lab, v. 46, n. 2, p. 99-104, 2010.

Helenice Gobbi

Professora associada de Anatomia Patológica da Faculdade de Medicina da Universidade Federal de Minas Gerais (UFMG) 